\title{
Wood chip drying in connection with combined heat and power or solar energy in Finland
}

\author{
Samuli Rinne a , Henrik Holmberg, Tiina Myllymaa, Kaisa Kontu and Sanna Syri \\ Department of Energy, Aalto University, PL 14100, 00076 Aalto, Finland
}

\begin{abstract}
Finnish district heating (DH) power plant fuels are wood-based and the share is increasing. The wood fuel demand probably exceeds the potential supply in the future. The wood fuel drying with waste heat is one profitable opportunity to gain more wood fuel. If the drying energy can be produced with lower primary energy use than combusting the fuel directly, the drying potentially improves the system efficiency. In this study, the drying feasibility in the connection of a combined heat and power (CHP) system, possibly with solar collectors, is calculated. The wood fuel heating can be increased profitably by $6 \%$, using the heat from CHP for drying only when the marginal cost of the heat is low enough, i.e. the electricity price is high enough and there is free capacity after the DH demand. Although the drying is profitable, a larger heat storage can also increase the annual result similarly. The best investment choice depends on the plant properties. Here the optimal system enables $20 \%$ DH production cost savings. Solar heat may be profitable, when the solar heat has a $2-3 \%$ share of the annual heat demand. However, the dryer or larger storage tank are more profitable investments.
\end{abstract}

\section{Introduction}

Drying of wood chips reduces storage losses and transportation cost and increases the lower heating value (LHV) of the wood fuel. The maximal increase of the LHV is in practice about $10-15 \%$, depending on the initial moisture content (MC) of the fuel. [1] If the wood is dried for example from 50\% MC to $20 \%$, the LHV increases from $0,81 \mathrm{MWh} /$ loose- $\mathrm{m}^{3}$ to $0,89 \mathrm{MWh} /$ loose- $\mathrm{m}^{3}$, i.e. $10 \%$. The LHV of dry wood is supposed to be $19,5 \mathrm{MJ} / \mathrm{kg}$ [1]. If waste heat streams can be used as a heat source for drying, biomass drying usually results in improved total system energy efficiency. Flue gas heat use is in many cases a part of the solution, possibly combined with superheated steam, see e.g. [2] or [3]. There are some cases in which the impact of drying to the CHP process is studied [4, 5], but they are rare. We study here if using only CHP heat for drying is feasible.

Primary energy definition in connection with district heating (DH) and combined heat and power (CHP) is generally described e.g. in the standard EN 15316-4-5. This standard gives an average primary energy factor of about 0,6 for the Finnish CHP heat, i.e. to produce one unit of CHP DH 0,6 units of fuel is used in the defined system level [6]. This is a rough generalisation, since in practice the value has a large variation depending on the plant properties and the timing of the heat energy use.

\footnotetext{
${ }^{a}$ Corresponding author: samuli.rinne@aalto.fi
}

This is an Open Access article distributed under the terms of the Creative Commons Attribution License 4.0, which permits unrestricted use, distribution, and reproduction in any medium, provided the original work is properly cited. 
Table 1. Wood fuels in Finland in 2012. Moisture is expressed on wet basis [1, 8].

\begin{tabular}{lcc}
\hline & Estimated average MC, \% & Annual amount, TWh \\
\hline Forest residues & 45 & 15,2 \\
Bark & 55 & 11,6 \\
Sawdust & 50 & 4,1 \\
Other by-products & 40 & 1,6 \\
Recovered wood fuels & 30 & 1,4 \\
Pellets and briquettes & 8 & 0,5 \\
\hline
\end{tabular}

In this study, the feasibility of the drying in the connection of a combined heat and power (CHP) system, possibly added with solar collectors, is calculated. A key issue studied here is the benefits achieved when adjusting the timing of the drying so that the capacity of the CHP and solar heat production is utilised in an optimal way. This means that the drying is done when there is free capacity after district heat production and the production cost of the drying heat is as cheap as possible, i.e. concerning the CHP process, the market price of electricity is as high as possible. Solar energy can be used when excess heat from the CHP plant is not available (e.g. the plant is shut down) or the excess heat from the plant does not cover heat demand of the drying. This, of course, requires that the dryer is equipped with solar collectors and the sun is shining. The research question is thus: "how much the wood fuel can be dried profitably if CHP or solar heat is used?"

\section{Wood fuel use in Finland}

The total primary energy supply in Finland is about $380 \mathrm{TWh} / \mathrm{a}$ and the use of wood fuels about $90 \mathrm{TWh} / \mathrm{a}[7,8]$. Similarly to other Northern European countries, increased biomass use is in a key position in Finland's plan to achieve the EU renewable energy target for 2020. The future increase potential for forest fuels is about $25 \mathrm{TWh} / \mathrm{a}$ in Finland, mainly in connection to forest industries and municipal CHP plants [9]. However, the additional potential be achieved by fuel drying has been neglected in Finland due to the poor economic profitability of the dryer investments. So far, fuel prices have been low, and as a consequence the biomass drying with waste energy is now very rare in Finland. The average prices of wood fuels in Finland have increased from $13 € / M W h$ to $20 €$ /MWh during the last 6 years [7] which can considerably improve the profitability of the dryer investment. The main driver for this development has been the higher demand of wood fuels. The average MC of wood fuels delivered to the Finnish power plants, according to the type of the fuel, is shown in Table 1. The average is around $45 \%$. In the table we also show the annual amounts of wood fuels in different plant types.

\section{The drying needs from the power plant point of view}

The energy wasted for the evaporation in the combustion process decreases accordingly to the decrease of the moisture content (MC) of the fuel, and, on the contrary, the cost of separate drying increases. MC of 25-30\% can be seen as a compromise between different moisture dependent properties of the wood fuel. When MC is lower than 30\%, the decomposition process slows down significantly and in 20-25\% MC decomposition rate is practically zero [10]. The dry mass losses are thus avoided and dry chips can be used as a large buffer storage. Also the potential greenhouse gas emissions as a consequence of the wet material decomposition during the storage can be reduced [11]. The risk for self-ignition may decrease with lower moisture content, since the decomposing biomass rises the temperature, sometimes above the ignition level. However, the most risky situation is when there are wet and dry biomasses side by side: the wet one warms up and ignites the dry one. The MC variation even in the same truck load of fuel can be tens of \%-units in the worst case and thus it is important to mix and dry the fuel evenly [12].

The drying rate decreases considerably when the moisture content is below $30 \%$ because almost all water is bounded water below this moisture content. This means that dryer dimensions and investment 
costs increase rapidly if very low moisture contents are desired. The lower limit of the feasible MC of the fuel is also set by the fire prevention measures in the power plants. In general about $30 \%$ is seen as a suitable, practical limit value for MC in this sense. The MC may have a significant influence on the operational parameters of the boiler. The larger purpose-built fluidised bed (FB) boilers, which are normal in the Finnish CHP plants, are designed to be capable of burning also moist biomasses. If e.g. the $\mathrm{MC}$ of the fuel is $30 \%$ instead of $45 \%$, the boiler efficiency in one case increases from $92 \%$ to about 93\% [13]. Taking into account all of these, the energy used for evaporation (or melting of the frozen wood), and the timing of it are the most important measures when calculating the feasibility of the fuel drying. Following, the research or design question here is not how to achieve some exact moisture content. The most relevant question in this case is how much the fuel can be dried profitably.

\section{The advantages of the heat use flexibility in the CHP or solar heat network}

The marginal cost of heat is not the same all the time. It depends on the price of electricity, which fluctuates a lot. For instance, in the Nordic electricity market in summer time these are periods when the marginal cost of electricity is that of nuclear power, i.e. about $10 € / \mathrm{MWh}$, the other extreme being winter cold spells when peak load GT's are in operation with marginal costs of above $100 € / \mathrm{MWh}$ [14, 15]. Further, drying is not necessarily obligated to be performed at some specific moment, but rather it can be done when there is cheap heat energy available. The impact of the timing of the energy use is often left out from feasibility studies, thus we concentrate here on it.

The logic behind using CHP heat instead of using directly produced heat is the same as in the usual space heating case. Using CHP heat leads to primary energy savings and emission reductions, if the CHP electricity produced together with CHP heat replaces more energy- and emission-intensive marginal electricity from the electricity network [14]. Solar heat, in turn, means direct fuels savings and is therefore feasible from a material efficiency point of view. In a CHP system, solar heat may be feasible most probably when it replaces separate heat production, mainly during low or peak load or in rapid heat load changes.

Our ex-ante assumption is that the timing of the heat consumption is crucial for the profitability of the process. The drying must be allocated to the hours when there is heat producing capacity left after covering the normal heating demand thus avoiding extra investments. In addition, CHP heat must be used as much as possible when the price of electricity is at its highest. The typical Finnish municipal CHP plants have about 5000 annual peak load operating hours, so there is room for the optimization of the timing of the drying. Thus, the drying can be seen as one way of storing heat, which in turn is a feasible way to even out e.g. the fluctuation of wind power [16]. The additional, flexible heat use by the dryer can smoothen the heat demand so that the need for start ups and shut downs and significant load changes of the plant is reduced.

\section{The simulated system and methods}

\subsection{The base case system and the input values}

The production system described here represents a modern state-of-art CHP system for solid fuel. In Finland these systems normally use FB technology with high steam values (e.g. 180 bar, $560{ }^{\circ} \mathrm{C}$ ) for wood fuel boiler and secondary superheater for steam reheat. These make a good power-to-heat-ratio of 0,6 for a wood fuelled CHP plant. The fuel input is supposed to be $100 \mathrm{MW}$, electrical output $33 \mathrm{MW}$ and heat output $55 \mathrm{MW}$. Figure 1 shows the layout of the system, with possible dryers and solar collectors.

This does not represent any existing system exactly, but presents a typical dimensioning of the system. However, the power-to-heat ratio is in many older and smaller plants less than 0,6 , which must 


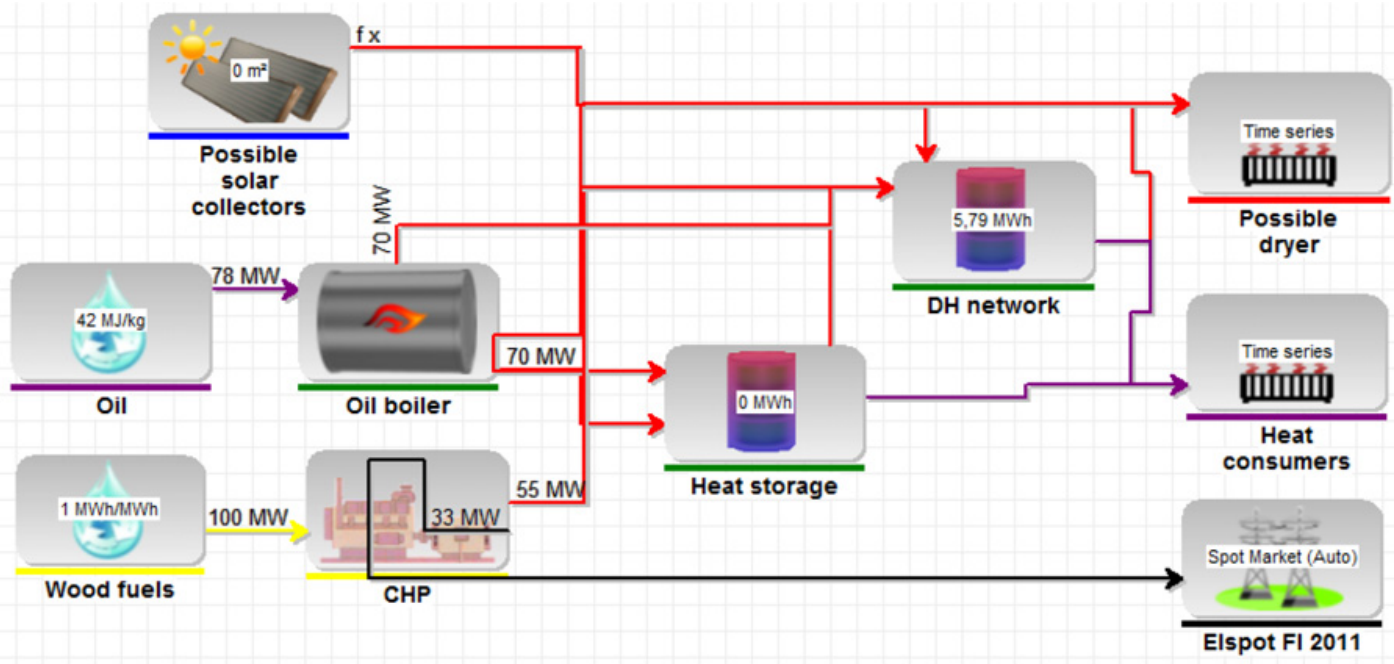

Figure 1. The layout of the studied system.

be noticed when generalising the results. The worse the power-to-heat ratio, the less profitable the drying with CHP heat is. The base case system has a heat storage. 2/3 of the Finnish CHP DH heat was produced in systems with heat storages in 2011 [17, 18]. The storage is usually a very profitable investment. In Table 2 the main properties of the base system are presented.

\subsection{The dryer}

The drying unit can be e.g. of batch or silo type or alternatively a belt dryer, see [22]. These types of dryers can also use low-temperature heat sources. In a silo type dryer, warm (or in some, especially smaller cases, cold) air is blown through the fuel bed in the silo. The belt dryer, in turn, has a slowly moving belt, through which the drying air is blown. We suppose here that a belt dryer is used. The maximum input heat effect was varied between 10 and $40 \mathrm{MW}$, i.e. between 20 to $70 \%$ of the CHP plant maximum heat input.

The dryer investment is based on the assumption that the hot water temperature supplied to the heat exchanger of the dryer is $80^{\circ} \mathrm{C}$, which is near to the average supply temperature of the typical DH system in Finland. The higher temperature would result in a cheaper dryer, but would also lead to the decrease of the power-to-heat ratio. The specific heat consumption of the dryer is supposed to be $4000 \mathrm{GJ} /$ tonne evaporated water, i.e. $60 \%$ of the hot water energy used for drying is gained as a form of better heating value of the biomass. The electricity use of the dryer blowers and other electricity equipment is supposed to be $1 / 40$ of the heat energy supplied to the dryer [23-26].

The following limitations are used for the hours that dryer is in the use:

- The net production price (marginal cost) of the heat is under $12 € / \mathrm{MWh}$. As the dryer can transfer about $60 \%$ of the input heat to the heat value increase of the dried fuel, this is the maximum heat energy cost for the profitable operation, when the fuel cost is $20 € / \mathrm{MWh}$.

- The sum of the heat use in the DH network and the heat effect fed to the dryer can be maximum $55 \mathrm{MW}$ (the maximum heat output of the CHP unit).

The downside of these limitations is that the annual operation hours of the dryer are reduced and to have the same output, the momentarily effect of the dryer must be consequently increased. Thus the capital cost of the dryer per output unit is higher. However, this is near the best possible operation 
Table 2. The main properties of the studied system.

\begin{tabular}{|c|c|c|}
\hline \multicolumn{3}{|l|}{ DH system } \\
\hline Annual heating energy & \multicolumn{2}{|l|}{$300 \mathrm{GWh}$} \\
\hline Heat demand & \multicolumn{2}{|l|}{$10 \ldots 110 \mathrm{MW}$} \\
\hline Location & \multicolumn{2}{|l|}{ Southern Finland } \\
\hline Outside temperature & \multicolumn{2}{|c|}{ Minimum $-26^{\circ} \mathrm{C}$, average $8^{\circ} \mathrm{C}$} \\
\hline Hot water temperature & \multicolumn{2}{|c|}{$75 \ldots 110^{\circ} \mathrm{C}[17]$, hottest in the cold weather, weighted avg $80^{\circ} \mathrm{C}$} \\
\hline Return water temperature & \multicolumn{2}{|c|}{$\begin{array}{l}44 \ldots 59^{\circ} \mathrm{C}[19], \text { coldest in the outside temp of } 0 \ldots 10^{\circ} \mathrm{C} \text {, } \\
\text { weighted average } 45^{\circ} \mathrm{C}\end{array}$} \\
\hline \multicolumn{3}{|l|}{ Energy production plants } \\
\hline & CHP plant & Oil boiler \\
\hline Fuel input & $30 \ldots 100 \mathrm{MW}$ & $0 / 78 \mathrm{MW}$ \\
\hline Electricity output & $10 \ldots 33 \mathrm{MW}$ & - \\
\hline Heat output & $16.5 \ldots 55 \mathrm{MW}$ & 0/70 MW \\
\hline Full load hours per year & 4700 in base case & 600 in base case \\
\hline Starting-up time & 4 hours & 0 \\
\hline Shutting down time & 4 hours & 0 \\
\hline Cost of start-up + shut down & 2000 euros & 0 \\
\hline Annual maintenance period & $24.6 .-22.7$ & - \\
\hline Fuel & $\begin{array}{l}\text { Wood fuels: forest residues, by- } \\
\text { products from forest industries }\end{array}$ & Heavy fuel oil \\
\hline Fuel price in average & 20 euros/MWh & $\begin{array}{l}79 \mathrm{e} / \mathrm{MWh} \text {, incl taxes and } \\
\text { carbon trade price }\end{array}$ \\
\hline Variable maintenance cost & 4 euros/MWh & 5 euros/MWh heat \\
\hline \multicolumn{3}{|l|}{ Heat storage tank } \\
\hline Volume & \multicolumn{2}{|l|}{$5000 \mathrm{~m}^{3}$, i.e. $150 \mathrm{MWh}$, in base case } \\
\hline Temperature in the bottom & \multicolumn{2}{|l|}{ Return temperature of $\mathrm{DH}+5 \mathrm{~K}$} \\
\hline Temperature in the top & \multicolumn{2}{|c|}{ Forward temperature of $\mathrm{DH}-5 \mathrm{~K}$ or $\max .98^{\circ} \mathrm{C}$} \\
\hline Storage loss & \multicolumn{2}{|c|}{ Noticed, insulation $300 \mathrm{~mm}$ mineral wool } \\
\hline Storage price & \multicolumn{2}{|c|}{$33 *$ volume $\left(\mathrm{m}^{3}\right)+400000 €[20]$} \\
\hline Lifetime & \multicolumn{2}{|c|}{20 years, interest rate in calculation $5 \%$, no residual value } \\
\hline \multicolumn{3}{|l|}{ Solar collector } \\
\hline Size & \multicolumn{2}{|l|}{$0 \ldots 100000 \mathrm{~m}^{2}$} \\
\hline Inclination and orientation & \multicolumn{2}{|l|}{$45^{\circ}$, South } \\
\hline Efficiency without losses & \multicolumn{2}{|l|}{$84 \%$} \\
\hline Thermal loss coefficient & \multicolumn{2}{|l|}{$3.77 \mathrm{~W} / \mathrm{m}^{2} \mathrm{~K}+0.012 \mathrm{~W} /\left(\mathrm{m}^{2} \mathrm{~K}\right)^{2}$} \\
\hline Temperature to collector & \multicolumn{2}{|l|}{$\mathrm{DH}$ return $+3 \mathrm{~K}$} \\
\hline Temperature from collector & \multicolumn{2}{|l|}{$\mathrm{DH}$ return $+13 \mathrm{~K}$} \\
\hline Collector price & \multicolumn{2}{|c|}{$200 € / \mathrm{m}^{2}[21]$} \\
\hline Lifetime & \multicolumn{2}{|c|}{20 years, interest rate in calculation $5 \%$, no residual value } \\
\hline
\end{tabular}

strategy, i.e. the unit is run always when the operation makes profit, calculated from marginal costs and income.

\subsection{EnergyPRO model}

The energy system studied here contains heat storage. Therefore the optimization cannot be done just hour by hour individually, but rather taking into account the optimal strategy for a longer time. The optimisation is here done by using the energyPRO software [27-29], which fulfills this requirement. It has been used in various cases for example in Denmark, see eg. [30-32], UK [33, 34] and Germany [35].

The idea of the optimisation is to find the plant operating pattern to fulfil the energy demand with the lowest annual operation cost. When performing the simulation, the model searches first the most profitable moments for energy production. The reason for this is that each new production has to 


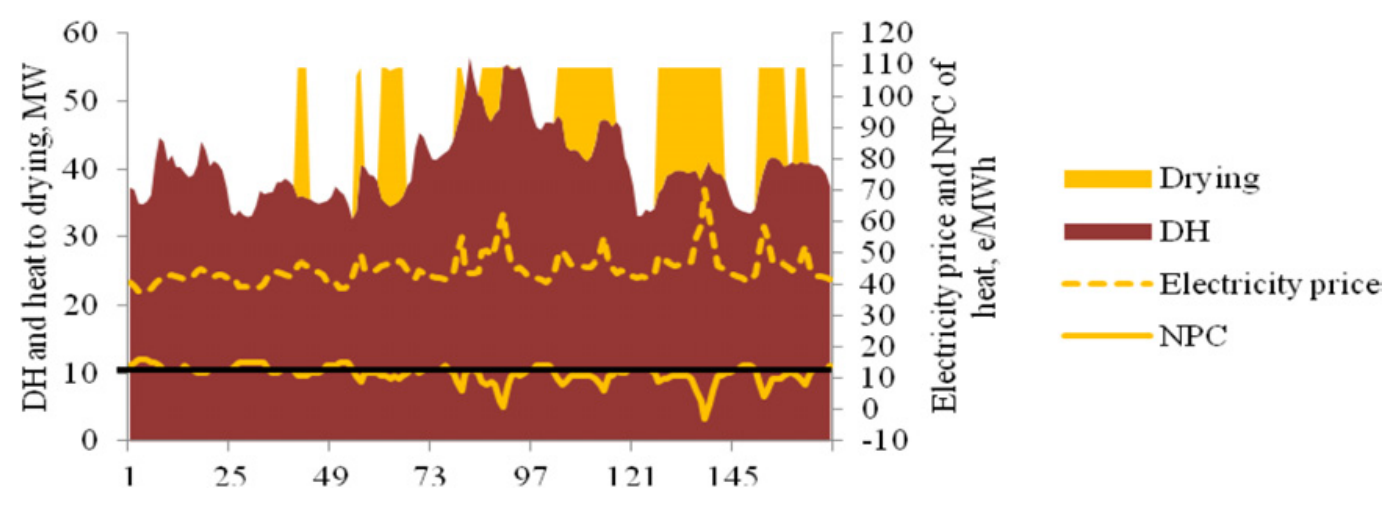

Figure 2. An example of the dryer use optimisation. Horizontal axis shows hours of one week. The red area shows the DH demand and the yellow area the heat use of the dryer. The dashed line is the electricity price and the continuous line net production cost (NPC) of heat. When the electricity price is high enough (NPC of the heat is low enough, here under $12 € / M W h)$, the dryer is used.

be carefully checked to avoid disturbing the already planned future production to avoid problems for example with varying electricity prices [33]. Concerning CHP, the production is most profitable when the electricity price is at highest. Also the start-up cost affects the issue, i.e. if the plant is not already running, it is not started for just one hour of profitable operation. We used hourly resolution in the modelling. Input values are either heat demand, cooling demand or/and electricity demand depending on the optimisation task. They also include information of environment (such as electricity prices, outdoor temperatures), fuels (such as heat values, possible restrictions, prices, etc.) and production units (such as production figures, minimum power, operarion\&maintenance costs, taxes, etc.).

\section{Results and discussion}

Figure 2 shows an example of the dryer use with the operation principles described here. The horizontal axis represents a time period of one week in October. This period shows a high electricity price variation between day and night. The dryer is mainly used when the electricity price is at its highest.

As a simulation result, we found that the most profitable alternatives are those with either $10000 \mathrm{~m}^{3}$ heat storage or $5000 \mathrm{~m}^{3}$ storage added with a dryer. When comparing these, it can be for example further calculated that the marginal cost of the drying energy is on average $6 € / M W h$. This cheap price is explained by e.g. the optimised timing of the drying.

In the most profitable sizing case, the maximum heat input to the dryer is 20-30 MW, about 30-50\% of the studied CHP plant full heat output. The annual heat use of the dryer is correspondingly 55-75 GWh, which means approx. 2500-3000 full load hours for the dryer. With this input, if the average MC of the incoming wood fuel is $45 \%$, after dryer it is consequently $28 \%$. This MC is a good compromise between energy efficiency and fire prevention. As a consequence of this kind of heat use for drying, the electricity production increases $20-25 \%$ while the DH output remains the same.

When varying the max. dryer heat input between $0 \ldots 40 \mathrm{MW}$ and the heat storage size between $3000 \ldots 10000 \mathrm{~m}^{3}$, the differences of the total annual cost between the alternatives, including investment payback and operation costs, are small, max. about 1 euros/MWh $\mathrm{DHNC}_{\mathrm{DPC}}$. Without heat storage or dryer, the annual cost is however about 3 euros/MWh higher, due to the decreased electricity production and heat-only oil boiler use, with no possibility to have some production flexibility.

Compared to the base case, $2-3 \%$ of the $\mathrm{DH}$ demand could be produced at least nearly profitably by solar heat with assumptions used here and when the return of the investment needed is low. This partly explains the increasing interest for solar heat in Finland even in the CHP networks, in addition to 
imago reasons. However, the investment in the dryer or heat storage is more profitable. Also, the dryer can increase the useful share of the solar heat significantly with large collectors, e.g. $20 \%$ in the case of $100000 \mathrm{~m}^{3}$ collector area. In this case, the solar share of the total heat supply is over $10 \%$.

When generalising the results, it must be remembered that the better the power-to-heat ratio, the better is the profitability of drying is using CHP heat. This limits the potential of drying in older and smaller CHP plants. There are also some uncertainties in the calculation method and basic data, which must be corrected when continuing the study. First, there should be more test years. Also the ramping up and down rates should be considered more precisely. Now they are noticed only when the plant is run down or started from a zero. Further, the investment data for drying equipment can be gathered more widely and the maintenance costs of the dryer must be noticed.

\section{Conclusions}

One overall goal in energy system planning is to find the solutions which cope well in the future environment of probably more fluctuating electricity prices and increasing use of residual biomass for energy. The price fluctuation is a consequence of the larger share of variable renewables (wind, solar), on one hand, and nuclear power with constant production, on the other hand, on the Nordic market.

There are many possibilities to handle the mismatch between the consumption and production timing. However, many of the stakeholders (both power plants and consumers) do not realise even well profitable investments. This is due to the lacking knowledge, transaction costs, high requirements for investment return rate etc. To achieve the ambitious goal, it is recommended to continue with the wide front, at least concerning the solutions that do not require massive R\&D efforts compared to the future potential. Wood fuel drying can be one of the mature and relatively cheap technologies in that sense.

In this study, two possible heat sources were available for the dryer: heat from the CHP plant or heat from solar collectors. Both of these concepts would already at present be competitive in countries with higher biomass prices than in Finland, e.g. in the Netherlands. Also in Finland, they can in many cases offer a less costly alternative to high-quality wood fuels such as pellets and torrefied biomass, which are currently under significant R\&D effort in Finland. In our calculations, the dryer drying in connection with CHP plant with smart drying timing seemed to be profitable even with the current Finnish wood fuel prices. Solar heat seems to be a slightly profitable investment in the base case with no drying, but if these investments are competing with each other, the drying alternative is more profitable. However, from e.g. the energy company image and brand point of view, solar heat may still be interesting. In the future, the rising fuel prices improve the competitiveness of solar energy.

\section{References}

[1] E. Alakangas. The properties of the fuels used in Finland. (In Finnish) http://www. vtt.fi/inf/pdf/tiedotteet/2000/T2045.pdf (2000)

[2] H. Li, Q. Chen, X. Zhang, K.H. Finney, V.N. Sharifi, J. Swithenbank. Evaluation of a biomass drying process using waste heat from process industries: A case study. Appl. Therm. Eng. 35 71-80 (2012)

[3] H. Song, E. Dotzauer, E. Thorin, J. Yan. Annual performance analysis and comparison of pellet production integrated with an existing combined heat and power plant. Case Study. Bioresource Technol. 102 6317-6325 (2011)

[4] J.P. Spets, P. Ahtila. Improving the power-to-heat ratio in CHP plants by means of a biofuel multistage drying system. Appl. Therm. Eng. 22 1175-1180 (2002)

[5] B. Wahlund, Y. Jinyue, M. Westermark. A total energy system of fuel upgrading by drying biomass feedstock for cogeneration: a case study of Skellefteå bioenergy combine. Biomass Bioenerg 23 271-281 (2002) 
[6] Finnish Association of Cicil Engineers RIL. Low-energy building construction. Residential buildings. (In Finnish) 291 p. (2010)

[7] Statistics Finland. Energy statistics Yearbook 2011. 151 p. http://stat.fi/til/ ene_en.html (2013)

[8] The Finnish Forest Research Institute. Forest statistics bulletin. The use of wood fuels in 2012. (In Finnish) http://www.metla.fi/metinfo/tilasto/julkaisut/mtt/2013/ puupolttoaine2012.pdf (2013)

[9] K. Kärhä, J. Elo, P. Lahtinen, T. Räsänen, S. Keskinen, P. Saijonmaa, H. Heiskanen, M. Strandström, H. Pajuoja. The availability and use of solid biofuels in Finland in 2020. (In Finnish) Ministry of Employment and the Economy. Energy and climate. 66/2010. http://www.tem.fi/files/28437/TEM_66_2010_verkkojulkaisu.pdf (2013)

[10] T. Thörnqvist. Fuel chips change during one year of storage. (In Swedish) Swedish University of Agricultural Sciences. Report No. 148, Uppsala (1983)

[11] M. Wihersaari. Evaluation of greenhouse gas emission risks from storage of wood residue. Biomass Bioenerg. 28 444-453 (2005)

[12] T. Järvinen. The Finnish adaptation of CEN sampling standard for solid biofuels. (In Finnish) Technical Research Centre of Finland. Technologial Research Report VTT-R-01322-12. http://energia.fi/sites/default/files/censov_tutkimusraportti_240412.pdf (2012)

[13] J. Kärki. Presentation in Forest Energy 2020-seminar in Joensuu, Finland 9.10.2013

[14] S. Rinne, S. Syri. Heat pumps versus combined heat and power production as $\mathrm{CO}_{2}$ reduction measures in Finland. Energy 57 308-318 (2013)

[15] Nord Pool Spot. Nordic Power Market. Web page. http://npspot.com

[16] J. Kiviluoma, P. Meibom. Influence of wind power, plug-in electric vehicles, and heat storages on power system investments. Energy 35 1244-1255 (2010)

[17] The Association of Finnish Energy Industries. The handbook of District Heating. (In Finnish) 566 p. (2006)

[18] The Association of Finnish Energy Industries. District Heating Statistics 2011. http:// energia.fi/sites/default/files/kaukolampotilasto_2011_web.pdf (2013)

[19] H. Parkkinen, C.J. Fogelholm. Possibilities of dropping outgoing and return temperatures of district heat in old networks. (In Finnish) Helsinki University of Technology. HUT/Eny. 87 p. (2001)

[20] J. Söderman, F. Pettersson, P. Ahtila, I. Keppo, A. Nuorkivi, K. Sipilä, J. Ikäheimo. DO²DES - Design of Optimal Distributed Energy Systems. Åbo Akademi University, Department of Chemical Engineering, Heat Engineering Laboratory. Report 2005-1. 58 p. (2005)

[21] M. Tahkokorpi, M. Hagström, J. Vanhanen. The possibilities of solar thermal energy in the district heating system. (In Finnish) Gaia Consulting Oy. http://energia.fi/ sites/default/files/aurinkokaukolammon_mahdollisuudet_gaia_2011.pdf (2013)

[22] J.G. Brammer, A.V. Bridgwater. Drying technologies for an integrated gasification bio-energy plant. Renew. Sust. Energ. Rev. 3 243-289 (1999)

[23] Stela Laxhuber. Personal information and web page. http://www.stela.de/en/products/ belt_drier/low-temperature-belt-dryer-for-sawdust-pellets-woo_fzv0yiuc.html (2013)

[24] Dorset. Web page. http://www.dorset.nu/en/page/home-gm/applications/dryingwood-chips-orsawdust.html (2013)

[25] V. Linna, T. Järvinen. Technical solutions and economy of the artificial drying of wood chips. (In Finnish) The Finnish Ministry of Trade and Industry, Energy Department. SITRA. Research Reprt No. 25 A. $114+5$ p. (1984) 
[26] V. Linna, H. Kaipainen, J. Okkonen. The use of solar energy in the blower drying of wood chips and sod peat. (In Finnish) Technical Research Centre of Finland, Research Reports 239. 128+7 p. (1983)

[27] EMD - EnergyPRO. Web page. http://emd.dk/energyPRo/Frontpage (2013)

[28] D. Connolly, H. Lund, B.V. Mathiesen, M. Leahy. A review of computer tools for analysing the integration of renewable energy into various energy systems. Appl. Energy 87 1059-82 (2010)

[29] L.R. Hinojosa, A.R. Day, G.G. Maidment, C. Dunham, P. Kirk. A comparison of combined heat and power feasibility models. Appl. Therm. Eng. 27 2166-72 (2007)

[30] H. Lund, A.N. Andersen. Optimal designs of small CHP plants in a market with fluctuating electricity prices. Energy. Convers. Manag. 46 893-904 (2005)

[31] P.A. Østergaard. Comparing electricity, heat and biogas storages' impacts on renewable energy integration. Energy 37 255-62 (2012)

[32] S. Nielsen, B. Möller. Excess heat production of future net zero energy buildings within district heating areas in Denmark. Energy 48 23-31 (2012)

[33] A. Fragaki, A.N. Andersen, D. Toke. Exploration of economical sizing of gas engine and thermal store for combined heat and power plants in the UK. Energy 33 1659-70 (2008)

[34] A. Fragaki, A.N. Andersen. Conditions for aggregation of CHP plants in the UK electricity market and exploration of plant size. Appl. Energy 88 3930-40 (2011)

[35] G. Streckiené, V. Martinaitis, A.N. Andersen, J. Katz. Feasibility of CHP-plants with thermal stores in the German spot market. Appl. Energy 86 2308-16 (2009) 